\title{
dspace.vutbr.cz
}

\section{Compensation methods of interturn short- circuit faults in dual three-phase PMSM}

\author{
KOZOVSKÝ, M.; BUCHTA, L.; BLAHA, P.
}

Proceedings of the IECON 2020 The 46th Annual Conference of the IEEE Industrial Electronics Society, pp. 689-693

elSBN: 978-1-7281-5413-8

ISSN: 2577-1647

DOl: https://doi.org/10.1109/IECON43393.2020.9254734

Accepted manuscript

(C2020 IEEE. Personal use of this material is permitted. Permission from IEEE must be obtained for all other uses, in any current or future media, including reprinting/republishing this material for advertising or promotional purposes, creating new collective works, for resale or redistribution to servers or lists, or reuse of any copyrighted component of this work in other works. KOZOVSKÝ, M.; BUCHTA, L.; BLAHA, P., "Compensation methods of interturn short-circuit faults in dual three-phase PMSM", Proceedings of the IECON 2020 The 46th Annual Conference of the IEEE Industrial Electronics Society, 2020. DOI: 10.1109/IECON43393.2020.9254734. Final version is available at https://ieeexplore.ieee.org/document/9254734 


\section{Compensation methods of interturn short-circuit faults in dual three-phase PMSM}

\author{
$1^{\text {st }}$ Matus Kozovsky \\ CEITEC \\ Brno University of Technology \\ Purkynova 123, 61200 Brno, Czech Republic Purkynova 123, 61200 Brno, Czech Republic \\ matus.kozovsky@ceitec.vutbr.cz \\ $2^{\text {nd }}$ Ludek Buchta \\ CEITEC \\ Brno University of Technology \\ ludek.buchta@ceitec.vutbr.cz
}

\author{
$3^{\text {rd }}$ Petr Blaha \\ CEITEC \\ Brno University of Technology \\ Brno, Czech Republic \\ petr.blaha@ceitec.vutbr.cz
}

\begin{abstract}
Permanent magnet synchronous machines (PMSM) are widely used for their high efficiency and power density. High machine reliability is increasingly required nowadays. PMSMs can't be simply disconnected from the power source unlike asynchronous machines if any fault appears in the system. Many motor faults lead to malfunction of the whole system. This limitation can be solved by using multi-phase structures instead of commonly used three-phase structures. Multi-phase machines have many advantages in terms of high reliability. The power density of properly designed multi-phase system is also higher. The multi-phase PMSM can operate even during a fault, under certain conditions, depending on the motor parameters. The control algorithm must be capable to detect the fault and apply proper control method according to the detected fault.

This paper demonstrates the behaviour of the dual three-phase PMSM motors under various inter-turn short circuit faults. An experimental PMSM was prepared, having stator windings with multiple taps. These winding taps are utilised to emulate interturn short circuit faults. The winding short-circuiting is realized by a solid-state relay. The fault influence is analysed on the experimental machine.
\end{abstract}

Three compensation strategies are applied to reduce the fault influence. All compensation strategies are based on field weakening of the damaged motor part. The motor behaviour during the fault without compensation method is compared with the behaviour when using compensation strategies. Realised experiments demonstrate that a properly constructed dual threephase PMSM under control with compensation strategies can continuously operate under the fault condition.

Index Terms-PMSM, dual three-phase, multi-phase, failoperation, inter-turn fault

\section{INTRODUCTION}

Permanent magnet synchronous machines (PMSM) are commonly used nowadays. These motors are used especially for high power density and efficiency. Especially three-phase variants are commonly used. Nevertheless, multi-phase PMSM has many advantages compared with standard three-phase PMSM. The multi-phase structure requires multi-phase power inverter. Using a multi-phase structure is allowed by decreasing costs of power components as well as by increased computing power of microcontrollers. Multi-phase structures

This work was supported by the ECSEL Joint Undertaking under Grant 737469 (AutoDrive).

This research has been financially supported by the Ministry of Education, Youth and Sports of the Czech republic under the project CEITEC 2020 (LQ1601). are typically used in combination with fully integrated power electronics to reduce a high number of power cables [1].

One of the biggest advantages of the multi-phase structure is the higher fault tolerance. Other undeniable benefits are smoother generated torque, higher winding factor and lower phase currents/voltages (according to stator winding arrangement). Mentioned properties are very important for advanced powertrains and other safety-critical applications.

The behaviour of the motor is generally closely related to the motor design [2]. However, the control algorithm structure is also important. Properly designed dual three-phase motor can operate under open-circuit fault [3], [4]. Interturn short circuit fault can be also handled using the dual three-phase arrangement if the field weakening index of the machine is lower than one [5].

A fault operational multi-phase motor can be connected to power inverter using several different topologies [6]. In [7], the motor coils are connected to individual H-bridges. Demonstrated solution is suitable in terms of inverter fault. Open phase faults are also easily solved using this structure, however, interturn short circuit fault influence inside of the machine cannot be overcome. This fault can cause an uncontrolled local thermal overload. The motor cannot continuously operate under this fault for this reason. This connection is suitable for three-phase motors to provide fail operation system under certain fault condition. Nevertheless, the mentioned approach can be also used for multi-phase structures. The sixphase machine needs twelve inverter legs to provide proper functionality of this arrangement.

The multi-phase motor can be also connected as one multiphase system [4]. This arrangement is also suitable for open phase faults. Power inverter with only six inverter legs is required compared with the previously mentioned arrangement. Short-circuit faults are hardly handled using this arrangement because all motor coils are connected into one complex system.

Another possible method how to connect the multi-phase motor is to divide coils into groups. We can form $\mathrm{n}$ times $\mathrm{k}$-phase structure. More specifically, the six-phase motor can be connected as a dual three-phase system. This arrangement also requires only six inverter legs, however, two partially separated sub-systems are formed. [5] demonstrates a solution 


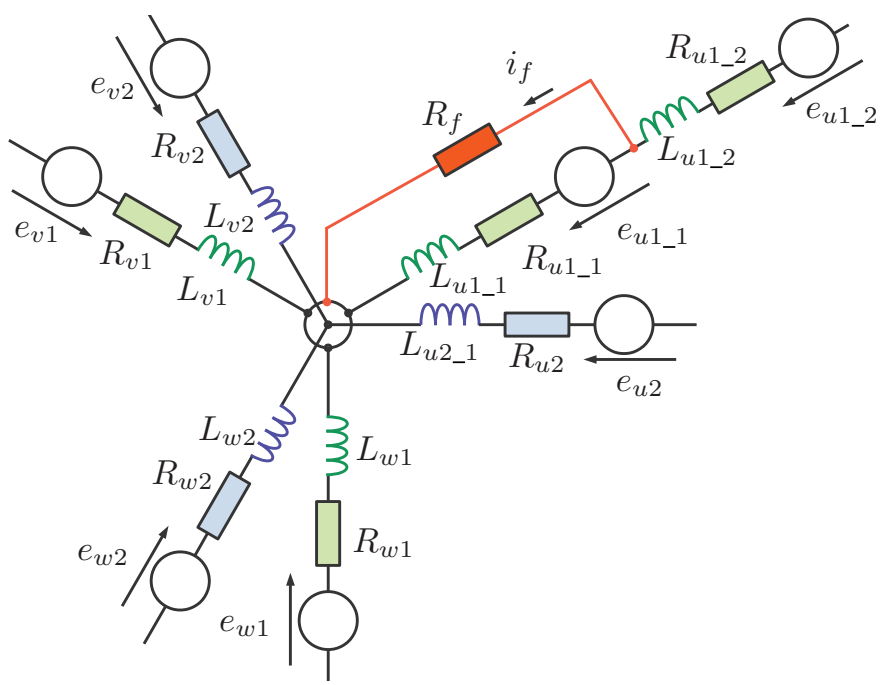

Fig. 1. Experimental motor winding arrangement with emulated fault

for the inverter short circuit fault. The whole sub-system is switched into an active short circuit (ASC) and the required motor torque is generated by the healthy sub-system. The same principle can be used to reduce the influence of an interturn short-circuit. The damaged motor sub-system is field weakened and the interturn fault current is reduced.

\section{MATHEMATICAL ANALYSIS OF PMSM INTERTURN SHORT CIRCUIT}

Interturn short-circuit is one of the most typical winding faults. This type of fault appears if the insulation between conductors in the same stator slot is punctured. Some literature sources denote this fault as turn-to-turn short-circuit fault. We can speak about turn-to-turn short-circuit if only one phase is damaged. One stator slot can accomodate two different phases. Connection of two different phases is well known as a phaseto-phase short-circuit.

This paper deals with turn-to-turn short-circuit within one motor coil. The fault current produced by interturn shortcircuit is represented by the signal $i_{f}$. The variable $R_{f}$ represents the resistance of the short-circuit point.

The stator winding of the experimental motor consists of 18 coils. Each stator coil is wind around one stator tooth. This arrangement is well known as a concentrated winding. The inductance, resistance and back-EMF constant of each stator coil are denoted by the symbols $L_{c}, R_{c}$ and $\lambda_{c}$ respectively.

The assignment of individual coils to sub-systems is shown in Figure 2. Fully symmetrical dual three-phase motor is achieved using this alignment. The first sub-system is represented by solid colours. Another sub-system is represented by hatched colours. One sub-system phase of the experimental motor is consists of three serially connected coils. Mutual inductance between adjacent coils is low due to the selected arrangement. The ratio of the number of short-circuited turns to the overall coil turns is represented by the interturn shortcircuit depth $\sigma$. The short-circuit depth affects fault current

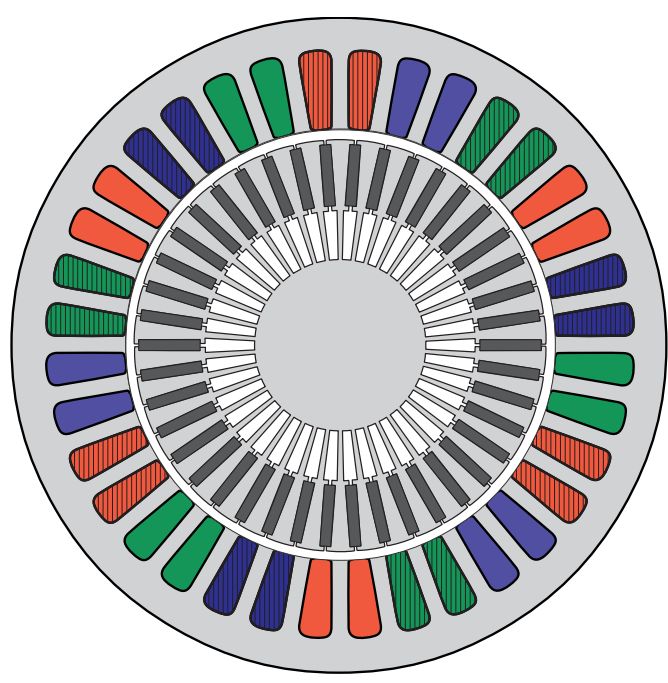

Fig. 2. Experimental motor winding arrangement

amplitude and vibrations generated by motor. Probability of short-circuit between two different slots is reduced by geometrical distance.

The inductance resistance and back-EMF of individual motor phase windings can be calculated using the following equations (1)-(3). Each phase winding is consist of three coils.

$$
\begin{aligned}
L_{p h} & =3 L_{c} \\
R_{p h} & =3 R_{c} \\
\lambda_{p h} & =3 \lambda_{c}
\end{aligned}
$$

The fault is emulated in the phase $u$. This phase is divided into two parts. The first part represents interturn short-circuit. The second part is the rest of the winding. The motor connection during the fault is shown in Figure 1. Inductance of individual winding parts and mutual inductance between the healthy and short circuited winding part can be calculated using equations (4)-(6) [8].

$$
\begin{aligned}
L_{u 1 \_1} & =\sigma^{2} L_{c} \\
L_{u 1 \_2} & =2 L_{c}+(1-\sigma)^{2} L_{c} \\
M_{u} & =\sigma(1-\sigma) L_{c}
\end{aligned}
$$

The same approach is used to determine the resistance and back-EMF constant of individual parts of the winding $u$ (7)(10).

$$
\begin{aligned}
R_{u 1 \_1} & =\sigma R c \\
R_{u 1 \_2} & =(3-\sigma) R_{c} \\
\lambda_{u 1 \_1} & =\sigma \lambda_{c} \\
\lambda_{u 1 \_2} & =(3-\sigma) \lambda_{c}
\end{aligned}
$$

The fault current depends on the actual electrical motor speed and interturn short-circuit depth. The resistance of the short-circuit point is also important. The fault current 
amplitude considering zero phase currents can be calculated using (11).

$$
I_{f}=\frac{\omega \lambda_{u 1 \_1}}{\sqrt{\omega^{2} L_{u 1 \_1}^{2}+\left(R_{u 1 \_1}+R_{f}\right)^{2}}}
$$

The fault current amplitude increases with the motor speed. The maximal fault current amplitude is given by the interturn short-circuit inductance and back-EMF constant. Assuming $\omega L_{u 1 \_1}$ is much larger than the resistance (12).

$$
I_{f} \approx \frac{\lambda_{u 1 \_1}}{L_{u 1 \_1}}
$$

The fault current can be obtained by combining (11),(4),(9),(7) into (13) as a function of short-circuit depth $\sigma$ for the analysed stator arrangement.

$$
I_{f}=\frac{\sigma \omega \lambda_{c}}{\sqrt{\left(\omega \sigma^{2} L_{c}\right)^{2}+\left(\sigma R_{c}+R_{f}\right)^{2}}}
$$

The fault current also depends on actual motor currents. The fault current is significantly reduced if the motor operates under field weakening. The previous equation can be extended to include actual motor $d q$ currents. The amplitude of the fault current can be calculated using (14).

$$
I_{f}=\frac{\sqrt{\omega^{2}\left(\sigma \lambda_{c}+\sigma(1-\sigma) L_{c} i_{d}\right)^{2}+\left(\sigma(1-\sigma) L_{c} i_{q}\right)^{2}}}{\sqrt{\left(\omega \sigma^{2} L_{c}\right)^{2}+\left(\sigma R_{c}+R_{f}\right)^{2}}}
$$

The similar principle can be applied on healthy three phasesubsystem. In this case we can speak about active short circuit (ASC). The motor is field weakened when it operates with ASC. The motor current required for full field weakening is denoted as a characteristic current of the motor. The characteristic current of the motor is lower than the current limit, assuming field weakening index smaller than one. It can be expressed by the equation (15).

$$
I_{c h}=\frac{\lambda_{p h}}{L_{d}}
$$

Each coil of the experimental motor consists of 25 turns. The highest interturn short-circuit current amplitude is theoretically generated by one short-circuited coil turn. The fault current amplitude can reach 25 times higher value than motor characteristic current for infinite speed. Extremely high motor currents generate heat which can damage adjacent coil turns. However the maximum motor speed is mechanically limited and the maximum fault current amplitude is generated by more short circuited coil turns.

\section{DUAL THREE-PHASE MOTOR COMPENSATION ANALYSIS}

The mathematical model of the classical three-phase motor can be extended to a dual three-phase model. This method is described in detail in [9]. The mutual coupling between subsystems is denoted by symbols $M_{d}$ and $M_{q}$. Symbols $L_{d}$ and $L_{q}$ represent motor inductances transformed into direct and quadrature axis. $u_{d_{\mathrm{S} j}}, u_{q_{\mathrm{S} j}}, i_{d_{\mathrm{S} j}}$ and $i_{q_{\mathrm{S} j}}$ denote motor voltages and motor currents transformed into $d q$ coordinates. The index $j$ represents the actual sub-system. The motor consists of two subsystems $j=\{1,2\}$. The symbol $\omega_{e}$ represents the actual electrical speed of the motor. This simplified model in $d q$ coordinates can be used for fully symmetrical motor constructions. The behaviour of the first motor sub-system can be described by the equation (16). The performance of the second sub-systems is the same because both sub-systems are identical.

$$
\begin{aligned}
u_{d_{\mathrm{S} 1}}= & R_{s} i_{d_{\mathrm{S} 1}}+L_{d} \frac{\mathrm{d} i_{d_{\mathrm{S} 1}}}{\mathrm{~d} t}+M_{d} \frac{\mathrm{d} i_{d_{\mathrm{S} 2}}}{\mathrm{~d} t} \\
& -\omega_{e}\left(L_{q} i_{q_{\mathrm{S} 1}}+M_{q} i_{q_{\mathrm{S} 2}}\right) \\
u_{q_{\mathrm{S} 1}}= & R_{s} i_{q_{\mathrm{S} 1}}+L_{q} \frac{\mathrm{d} i_{q_{\mathrm{S} 1}}}{\mathrm{~d} t}+M_{q} \frac{\mathrm{d} i_{q_{\mathrm{S} 2}}}{\mathrm{~d} t} \\
& +\omega_{e}\left(\Psi_{M}+L_{d} i_{d_{\mathrm{S} 1}}+M_{d} i_{d_{\mathrm{S} 2}}\right)
\end{aligned}
$$

The field weakening index of the experimental motor is lower than one, so the motor can continuously operate with ASC. ASC currents can be calculated by assuming zero $u_{d}$, $u_{q}$ voltages. The following equation (17) is obtained for the currents of the motor with ASC.

$$
\begin{aligned}
& i_{d_{A S C}}=-\frac{\omega_{e}^{2}\left(L_{q}+M_{q}\right) \Psi_{M}}{\omega_{e}^{2}\left(L_{d}+M_{d}\right)\left(L_{q}+M_{q}\right)+R_{s}^{2}} \\
& i_{q_{A S C}}=-\frac{R_{s} \omega_{e} \Psi_{M}}{\omega_{e}^{2}\left(L_{d}+M_{d}\right)\left(L_{q}+M_{q}\right)+R_{s}^{2}}
\end{aligned}
$$

The mutual coupling between sub-systems is very important when we are targeting fail operational behavior. Using the motor with low mutual inductances, the fault can be isolated in one motor sub-system while the other one can operate normally. Our experimental motor has the concentrated winding. In such a case we speak about the motor with low mutual inductances. The following equation (18) describes currents of ASC sub-system as a function of currents of the healthy one.

$$
\begin{aligned}
i_{d_{A S C}} & =\frac{R_{s} \omega_{e} M_{q} i_{q}^{s_{2}}-\omega_{e}^{2} L_{q q}\left(M_{d} i_{d}^{s_{2}}+\Psi_{M}\right)}{\omega_{e}^{2} L_{d} L_{q}+R_{s}^{2}} \\
i_{q_{A S C}} & =-\frac{R_{s} \omega_{e}\left(M_{d} i_{d}^{s_{2}}+\Psi_{M}\right)+\omega_{e}^{2} L_{d} M_{q} i_{q}^{s_{2}}}{\omega_{e}^{2} L_{d} L_{q}+R_{s}^{2}}
\end{aligned}
$$

\section{EXPERIMENTAL RESULTS}

Table I shows parameters of the experimental motor. The experimental motor has four taps prepared in one coil. This coil is divided in the ratio $1: 1: 3: 6: 14$. Ten different short circuit depths can be emulated using this arrangement. The short-circuit is realized by using the fault insertion unit (FIU) based on galvanically separated solid state relay with internal resistance $R_{f}=0.05 \Omega$ with the IC for current measurement. The disassembled experimental motor is shown in Figure 3. The motor connection to the test bench is shown is Figure 4. The test bench consists of the experimental dual threephase motor mechanically coupled with the dynamometer. The power inverter uses multiple three-phase power stages connected to the control board with three-core AURIX TC275 


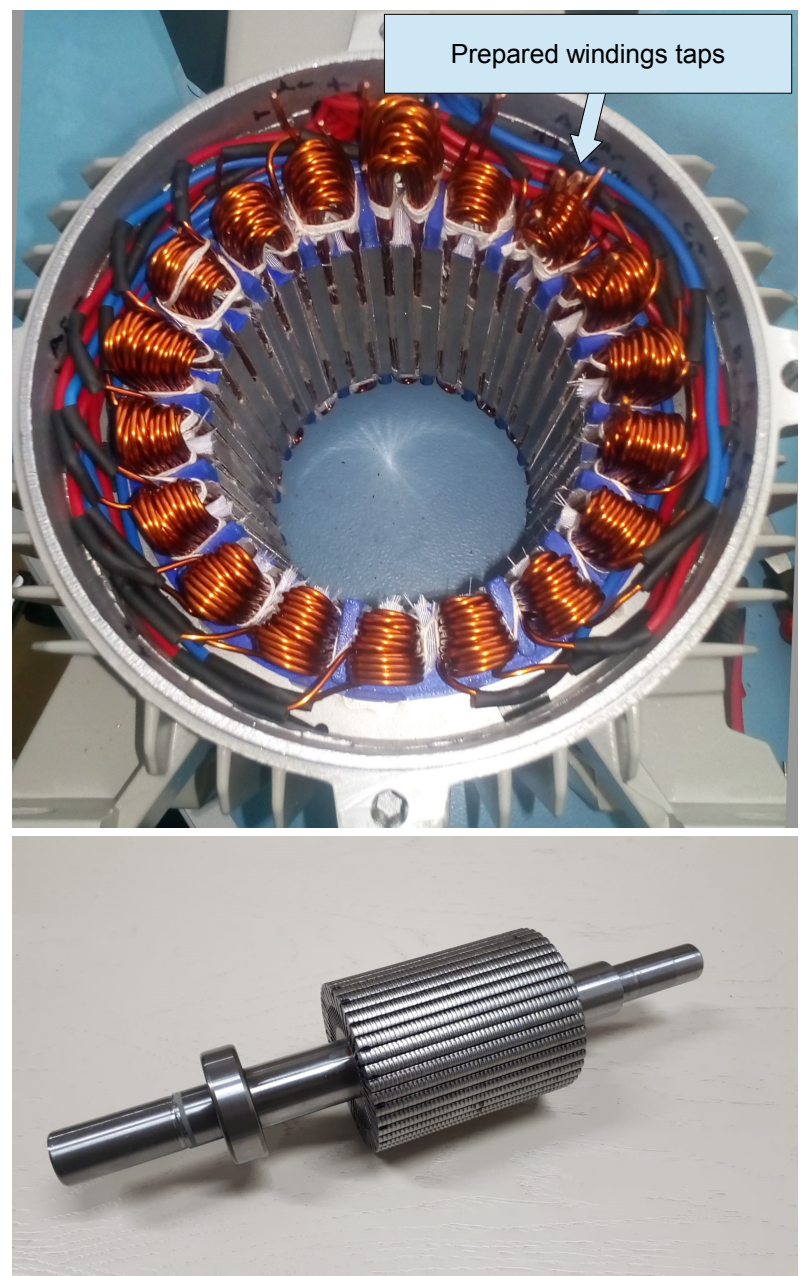

Fig. 3. Experimental motor stator (top) and rotor with permanent magnets (bottom)

microcontroller. Two cores are dedicated for control algorithm (one per subsystem) and the last core is used for the data acquisition using Ethernet.

Different interturn short-circuit faults are generated in a motor during the tests. The motor behaviour during the fault is compared with the behaviour when three different compensation strategies are applied.

Motor setpoints are configured to $i_{d}=i_{d r}, i_{q}=i_{q r} / 2$ during the normal operation without compensation. Variables $i_{d r}$ and $i_{q r}$ represent required $d$ and $q$ axis currents. Both sub-systems generate the same torque in this case.

The first compensation strategy switches the damaged subsystem into ASC mode. The motor can continuously operate in this mode because the fault current is reduced below the maximum motor current. However, the ASC mode generates constant breaking torque. The breaking torque depends on the actual motor speed. This torque can be compensated by the active sub-system, nevertheless the available power of the motor is reduced below one half of the maximum power.

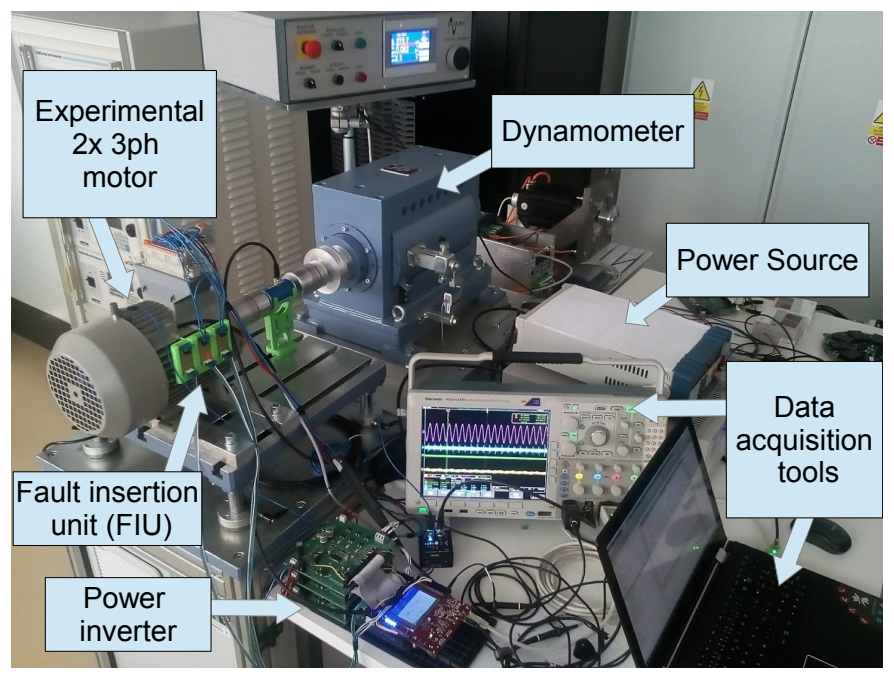

Fig. 4. Experimental motor connected to the dynamometer

The second compensation method uses active field weakening (AFW). In this case, the damaged sub-system is field weakened by the control algorithm. Current setpoints are configured to $i d=-i_{c h}, i q=0$. The breaking torque of this compensation method is zero and maximum motor torque during the fault can be higher comparing with the first method. The motor torque is generated only by the healthy sub-system in this case.

The last compensation method combines field weakening with the normal motor run (AFW with reduced power). Motor setpoints for damaged sub-system are $i d=-i_{c h}, i q=i_{r q} / 3$. Setpoints for the healthy sub-system are set to $i_{d}=i_{d r}$, $i_{q}=i_{q r} 2 / 3$. The damaged sub-system generates lower torque comparing with the healthy sub-system. The maximum motor power is reduced significantly less than during other compensation methods. Maximum allowed motor current limits must be respected in both-subsystems. The maximum $q$ current is therefore limited to $\pm 2.6 \mathrm{~A}$.

The influence of the interturn-short circuit depth was measured for two different motor speeds. The motor fault current

TABLE I

PARAMETERS OF EXPERIMENTAL MOTOR

\begin{tabular}{llll}
\hline Name & Symbol & Value & Unit \\
\hline DC voltage & $U_{D C}$ & 55 & $\mathrm{~V}$ \\
Maximum motor current & $i_{\max }$ & 6 & $\mathrm{~A}$ \\
Winding resistance & $R_{s}$ & 0.45 & $\Omega$ \\
Back-EMF constant & $\lambda_{p h}$ & 0.00989 & $\mathrm{~V}$ s/rad \\
d-axis inductance & $L_{d}$ & 1.84 & $\mathrm{mH}$ \\
q-axis inductance & $L_{q}$ & 1.98 & $\mathrm{mH}$ \\
d-axis mutual inductance & $M_{d}$ & 75 & $\mu \mathrm{H}$ \\
q-axis mutual inductance & $M_{q}$ & 163 & $\mu \mathrm{H}$ \\
Nominal speed & $\omega_{N}$ & 950 & $\mathrm{rpm}$ \\
Maximum speed & $\omega_{\max }$ & 3500 & $\mathrm{rpm}$ \\
Nominal power & $P_{N}$ & 270 & $\mathrm{~W}$ \\
Number of pole pairs & $P p$ & 21 & - \\
Characteristic current & $\mathrm{I}_{c h}$ & 5.4 & $\mathrm{~A}$
\end{tabular}




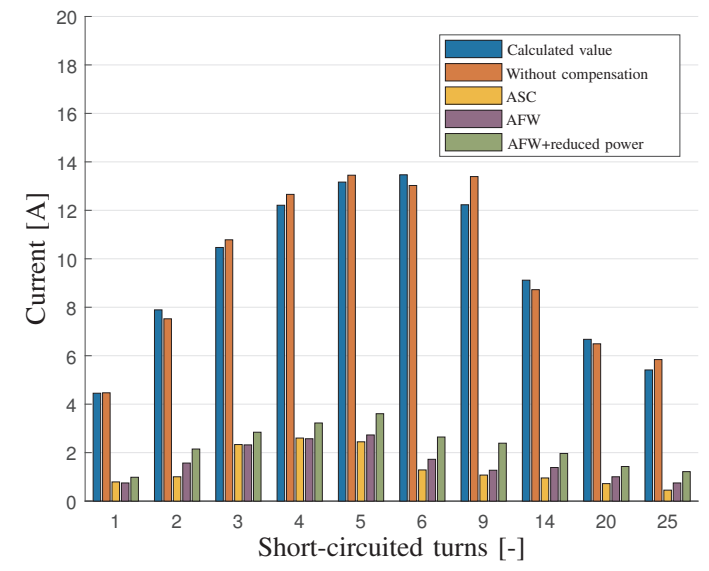

Fig. 5. Interturn fault current amplitude measured at 2000 rad $/ \mathrm{s}$ for different operation modes

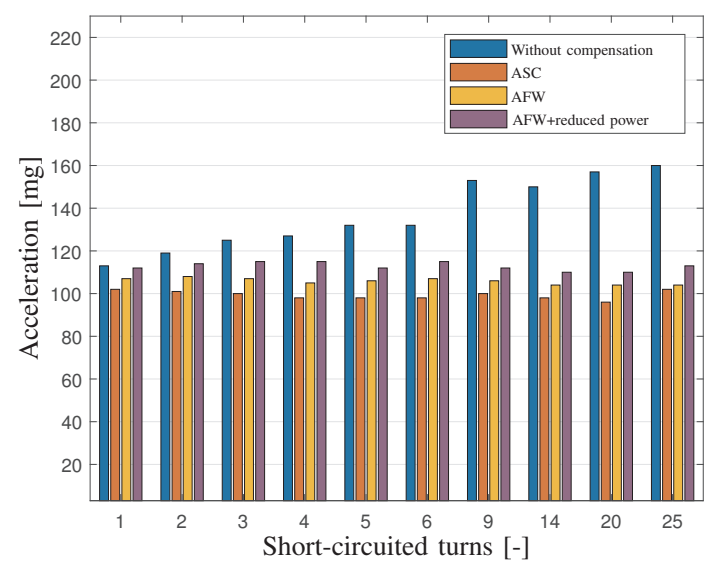

Fig. 6. Overall wideband vibration acceleration measured at $2000 \mathrm{rad} / \mathrm{s}$ for different operation modes

and overall wideband vibrations are measured during the tests. The measured current is compared with the calculated value of the fault current. The equation (14) and motor parameters from Table I were used for its calculation.

The first measurement was acquired during the electrical motor speed of $2000 \mathrm{rad} / \mathrm{s}$ without the load torque. This speed is almost equal to the nominal motor speed. The motor can reach this speed without the field weakening. The maximum allowed motor current is 6A. Measurement results for this speed are shown in Figures 5 and 6.

The fault current amplitude which is higher than the current limit can damage the motor. The motor in such a situation can't continuously operate under this fault without the compensation. The highest measured fault current is $13.5 \mathrm{~A}$ for six short-circuited turns. This value is more than 2 times higher than the maximum motor current. The small fault current amplitude for low number of short-circuited turns is caused by the high resistance of short-circuit point $R_{f}$. The fault current is significantly higher if the short-circuit happens inside of the motor. The figure 5 also shows the fault current amplitude using compensation strategies. All compensation strategies reduce the fault current under $6 \mathrm{~A}$. Vibrations generated by

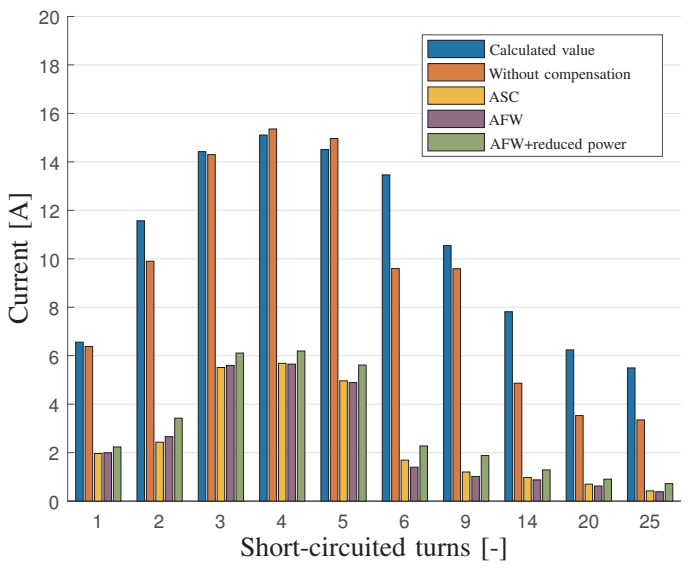

Fig. 7. Interturn fault current amplitude measured at $5000 \mathrm{rad} / \mathrm{s}$ for different operation modes

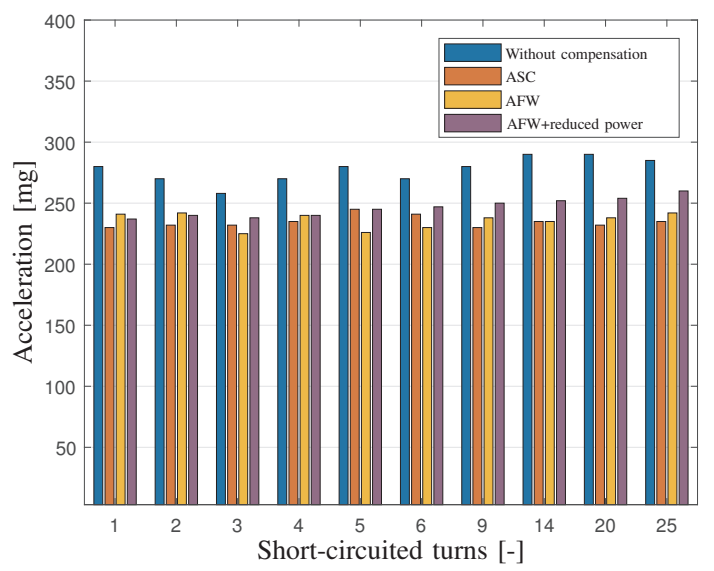

Fig. 8. Overall wideband vibration acceleration measured at $5000 \mathrm{rad} / \mathrm{s}$ for different operation modes

the motor shown in Figure 6 are also significantly reduced by using compensation methods. The lowest vibrations were measured using ASC compensation.

Another measurement was realised for the electrical motor speed of $5000 \mathrm{rad} / \mathrm{s}$. The motor must operate under the field weakening so as to reach this speed. The influence of the interturn short-circuit depth to fault current is shown in Figure 7. Figure 8 shows vibrations using the individual compensation strategies.

Further tests were realised with a fully loaded motor. These measurements show the influence of individual compensation methods to maximum achievable motor torque (Figure 10) and power (Figure 9). The influence of compensation methods to the fault current can be seen in Figure 11. Six shortcircuited turns were used during the tests. Highest fault current amplitude can be seen for motor operation without field weakening.

\section{CONCLUSION}

Realised measurements confirm that the motor can continuously operate when using one of the presented compensation methods. Otherwise the fault current caused by the interturn 


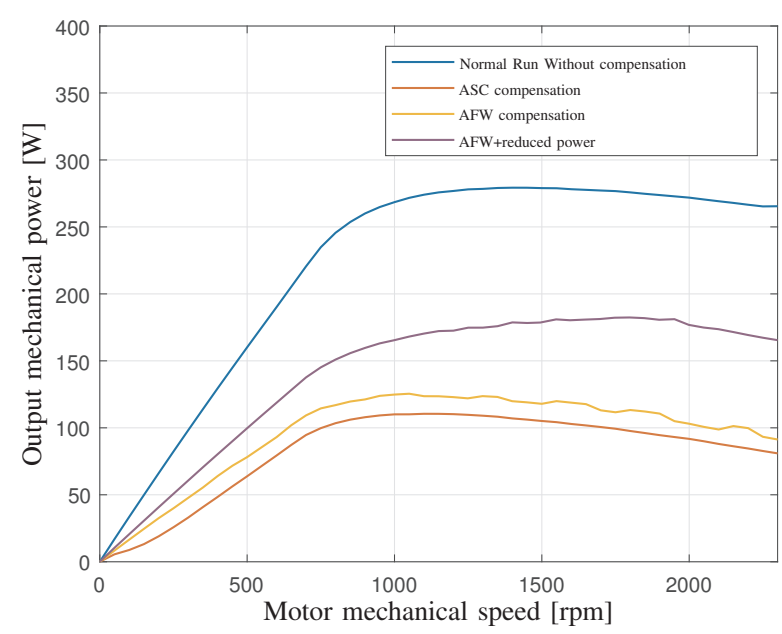

Fig. 9. Maximum achievable motor output mechanical power for individual compensation methods

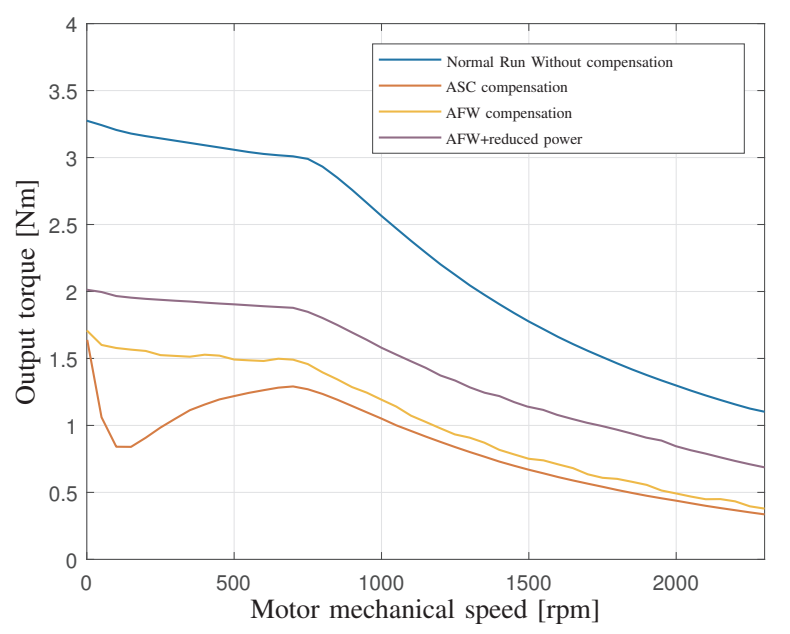

Fig. 10. Maximal achievable motor torque for individual compensation methods

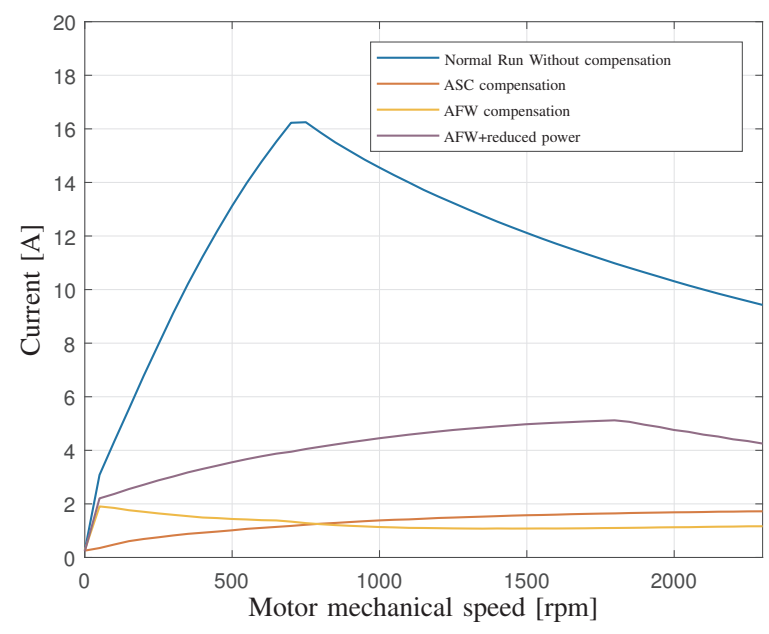

Fig. 11. Motor fault current amplitude for six short circuited turns. short-circuit is too high and it can cause the thermal motor damage.

The same compensation methods can be used for phase to phase short-circuit faults. In this case, its position is decisive for the proper compensation method selection.

Realised measurements confirm that the lowest power can be generated using the most simple ASC compensation method. The major disadvantage of this method is the low torque in the low speed area as it is shown in Figure 10. This behaviour is caused by high $q$ axis current in the low speed area (18). On the other hand, the fault current is significantly reduced.

The AFW compensation method eliminates problems in the low speed area but the maximum achievable power is only partially increased.

The highest motor power can be reached by using AFW with reduced power. The Motor can generate approximately $65 \%$ of its normal power. The fault current is reduced and stays below the maximum motor current for all implemented and tested compensation strategies.

\section{REFERENCES}

[1] A. Kilic, J. Faßnacht, T. Shen, and C. Thulfaut, "Failoperational Powertrain for Future Mobility," MTZ worldwide, vol. 80, no. 9, pp. 66-70, sep 2019. [Online]. Available: http://link.springer.com/10.1007/s38313-019-0089-x

[2] F. Wu, P. Zheng, and T. M. Jahns, "Analytical Modeling of Interturn Short Circuit for Multiphase Fault-Tolerant PM Machines With Fractional Slot Concentrated Windings," IEEE Transactions on Industry Applications, vol. 53, no. 3, pp. 1994-2006, may 2017. [Online]. Available: http://ieeexplore.ieee.org/document/7845684/

[3] Hyung-Min Ryu, Ji-Woong Kim, and Seung-Ki Sul, "Synchronous-frame current control of multiphase synchronous motor under asymmetric fault condition due to open phases," IEEE Transactions on Industry Applications, vol. 42, no. 4, pp. 1062-1070, 2006. [Online]. Available: http://ieeexplore.ieee.org/document/1658337/

[4] D. Casadei, M. Mengoni, G. Serra, A. Tani, and L. Zarri, "Optimal fault-tolerant control strategy for multi-phase motor drives under an open circuit phase fault condition," in 2008 18th International Conference on Electrical Machines. IEEE, sep 2008, pp. 1-6. [Online]. Available: http://ieeexplore.ieee.org/document/4800094/

[5] P. Giangrande, V. Madonna, S. Nuzzo, C. Gerada, and M. Galea, "Braking Torque Compensation Strategy and Thermal Behavior of a Dual Three-Phase Winding PMSM During Short-Circuit Fault," in 2019 IEEE International Electric Machines \& Drives Conference (IEMDC). IEEE, may 2019, pp. 2245-2250. [Online]. Available: https://ieeexplore.ieee.org/document/8785164/

[6] M. Gleissner, J. Haring, W. Wondrak, and M.-M. Bakran, "Reconfiguration of fault-tolerant inverters with reduced maximum output voltage or current in combination with permanent magnet synchronous machines," in 201921 st European Conference on Power Electronics and Applications (EPE'19 ECCE Europe). IEEE, sep 2019, pp. P.1-P.10. [Online]. Available: https://ieeexplore.ieee.org/document/8914957/

[7] M. Villani, M. Tursini, G. Fabri, and L. Castellini, "Multi-phase permanent magnet motor drives for fault-tolerant applications," in 2011 IEEE International Electric Machines \& Drives Conference (IEMDC). IEEE, may 2011, pp. 1351-1356. [Online]. Available: http://ieeexplore.ieee.org/document/5994802/

[8] L. Otava, M. Graf, and L. Buchta, "Interior Permanent Magnet Synchronous Motor Stator Winding Fault Modelling," IFACPapersOnLine, vol. 48, no. 4, pp. 324-329, 2015. [Online]. Available: https://linkinghub.elsevier.com/retrieve/pii/S2405896315008307

[9] M. Kozovsky, P. Blaha, and P. Vaclavek, "Verification of nine-phase PMSM model in d-q coordinates with mutual couplings," in 2016 6th IEEE International Conference on Control System, Computing and Engineering (ICCSCE). IEEE, 2016, pp. 73-78. 